\title{
A comparison of hospital and nonhospital colonoscopy: Wait times, fees and guideline adherence to follow-up interval
}

\author{
Noah Ivers $\mathrm{MD}^{1,2}$, Michael Schwandt $\mathrm{MD}^{1,3}$, Susan Hum MSc${ }^{1}$, Danielle Martin $\mathrm{MD}^{1,2}$, \\ jill Tinmouth MD PhD ${ }^{4,5}$, Nick Pimlott MD PhD ${ }^{1,2,3}$
}

N Ivers, M Schwandt, S Hum, D Martin, J Tinmouth, N Pimlott. A comparison of hospital and nonhospital colonoscopy: Wait times, fees and guideline adherence to follow-up interval. Can J Gastroenterol 2011;25(2):78-82.

BACKGROUND: Although colonoscopy is increasingly performed in nonhospital facilities, studies to date examining differences between colonoscopy services in hospital and nonhospital settings have been limited, in large part, to administrative databases.

OBJECTIVES: To describe the experiences of patients receiving colonoscopy in hospital and nonhospital settings, and to compare these settings with respect to wait times and recommended follow-up interval to the next colonoscopy.

METHODS: A postal survey of 2000 patients, 50 to 70 years of age, from an urban academic family practice was conducted. Most recent colonoscopy was classified as either occurring in a hospital or nonhospital setting. Multivariable logistic regression analysis was used to examine the association among wait times, follow-up intervals and patient factors with respect to colonoscopy setting.

RESULTS: Patients who underwent their most recent colonoscopy outside of a hospital were more likely to be men $(\mathrm{P}=0.01)$ and to have undergone more than one previous colonoscopy $(\mathrm{P}=0.02)$. For patients with a normal screening colonoscopy and no family history of colorectal cancer or polyps, nonhospital clinics less often recommended a 10-year follow-up interval (OR 0.13 [95\% CI 0.04 to 0.47]). Reported wait times at nonhospital clinics were shorter for patients receiving screening colonoscopy (OR 2.11 [95\% CI 1.28 to 3.47]), but not for symptomatic patients (OR 1.74 [95\% CI 0.88 to 3.43]). For individuals attending nonhospital clinics, $10 \%$ were referred from a hospital by the same specialist performing the procedure; $31.7 \%$ reported paying a fee.

CONCLUSION: Nonhospital clinics were far less likely to adhere to guidelines regarding follow-up intervals for low-risk patients. Given the implications for both health care costs and patient safety, further study is needed to determine the cause of this disparity.

Key Words: Colonoscopy; Health care surveys; Quality of health care

C olorectal cancer (CRC) is the second most common cause of cancer-related mortality in Canada (1), but screening using fecal occult blood testing (FOBT) (2) and flexible sigmoidoscopy (3) can reduce CRC-related mortality. The demand for colonoscopy has dramatically increased over the past decade because in large part, it is more sensitive than FOBT and flexible sigmoidoscopy (4). In Ontario, this growing demand has led to increasing numbers of colonoscopies performed in nonhospital settings; these clinics more often serve younger, wealthier and healthier men (5). Physicians performing colonoscopies in nonhospital settings can bill the provincial health insurance plan. However, unlike hospitals, nonhospital facilities
Une comparaison entre la coloscopie en milieu hospitalier et hors du milieu hospitalier : Temps d'attente, frais et respect des directives quant aux intervalles de suivi

HISTORIQUE : La coloscopie est de plus en plus effectuée dans des installations non hospitalières. Pourtant, jusqu'à maintenant, les études qui portent sur les différences entre les services de coloscopie en milieu hospitalier et hors du milieu hospitalier se limitent en grande partie à des bases de données administratives.

OBJECTIFS : Décrire les expériences des patients qui subissent une coloscopie en milieu hospitalier ou hors du milieu hospitalier et comparer ces milieux pour ce qui est des temps d'attente et de l'intervalle de suivi recommandé jusqu'à la coloscopie suivante.

MÉTHODOLOGIE : Les chercheurs ont mené une enquête postale auprès de 2000 patients de 50 à 70 ans d'une pratique familiale universitaire en milieu urbain. Ils ont classé la coloscopie la plus récente comme ayant eu lieu en milieu hospitalier ou non hospitalier. Ils ont utilisé la régression logistique multivariable pour examiner l'association entre le lieu de la coloscopie et les temps d'attente, les intervalles de suivi et les facteurs relatifs au patient.

RÉSULTATS : Les patients qui avaient subi leur coloscopie la plus récente hors du milieu hospitalier étaient plus susceptibles d'être des hommes $(\mathrm{P}=0,01)$ et d'avoir subi plus d'une coloscopie auparavant $(\mathrm{P}=0,02)$. Chez les patients dont la coloscopie de dépistage était normale et qui n'avaient pas d'antécédents de cancer colorectal ou de polypes, les cliniques non hospitalières recommandaient moins souvent un intervalle de suivi de dix ans (risque relatif [RR] 0,13 [95 \% IC 0,04 à 0,47]). Les temps d'attente déclarés dans les cliniques non hospitalières étaient plus courts pour les patients qui recevaient une coloscopie de dépistage (RR 2,11 [95\% IC 1,28 à 3,47]), mais pas pour les patients symptomatiques (RR 1,74 [95 \% IC $0,88$ à 3,43$]$ ). Dix pour cent des personnes qui fréquentaient une clinique non hospitalière avaient été aiguillées d'un hôpital par le spécialiste qui effectuait l'intervention et $31,7 \%$ ont déclaré payer des frais.

CONCLUSION : Les cliniques non hospitalières étaient beaucoup moins susceptibles de respecter les directives relatives aux intervalles de suivi auprès des patients peu vulnérables. Étant donné les répercussions à l'égard des frais de santé tout autant que de la sécurité des patients, d'autres études s'imposent pour déterminer la cause de cette disparité.

receive minimal government funding to cover the significant overhead costs (6) of providing colonoscopy services. Although the Canada Health Act forbids these clinics from charging patients for the actual procedure, they may be asked to pay voluntary fees for ancillary services.

Studies $(7,8)$ report that the quality of colonoscopies delivered in nonhospital settings in Ontario may be inferior to those delivered in hospitals with respect to $\mathrm{CRC}$ screening. However, research regarding colonoscopy provided out of hospital has been conducted, in large part, using administrative data. To address some of the limitations of such studies, we conducted a large-scale postal survey to answer the

${ }^{1}$ Family Practice Health Centre, Women's College Hospital; ' Department of Family and Community Medicine, University of Toronto;

${ }^{3}$ Dalla Lana School of Public Health, University of Toronto; ${ }^{4}$ Division of Gastroenterology, Department of Medicine, Sunnybrook

Health Sciences Centre; ${ }^{5}$ Division of Gastroenterology, Department of Medicine, University of Toronto, Toronto, Ontario

Correspondence: Dr Noah Ivers, Women's College Hospital, 60 Grosvenor Street, Toronto, Ontario M5S 1B2. Telephone 416-323-6400 ext 4581,

fax416-323-6350,e-mail noah.ivers@utoronto.ca

Received for publication July 25, 2010. Accepted September 11, 2010 
following questions: Are patients who undergo colonoscopy in a nonhospital setting more likely to be recommended earlier colonoscopy follow-up than those receiving the procedure in hospitals? Do patients wait longer for nonhospital-based colonoscopies than patients receiving colonoscopy in hospitals? Are patients in nonhospital settings asked to pay fees?

\section{METHODS}

\section{Participants}

A total of 2000 patients between 50 and 70 years of age were randomly selected from the patient roster of a comprehensive academic family practice in Toronto (Ontario), serving more than 22,000 patients with 70,000 patient visits per year.

\section{Data collection}

A six-page questionnaire was developed to collect data regarding participants' demographic characteristics (eg, age, sex, ethnicity, marital status, income and education), family history of CRC (yes, no or do not know) or colonic polyps (yes, no or do not know) and information regarding each participant's most recent colonoscopy. With respect to the latter, interest centred on the indication for the procedure (screening, symptomatic or positive FOBT), setting (hospital versus nonhospital), wait time (less than four weeks, four to eight weeks, or greater than eight weeks), results (normal, polyp[s], cancer, uncertain and/or other) and follow-up interval (less than three years, three to five years, six to nine years, 10 years, or uncertain). For individuals attending nonhospital clinics, interest centred on the source of referral (family physician recommendation, executive physical, specialist self-referral from public hospital, other physician referral, patient request or self referral), payment of fees (yes or no), whether fees were perceived to be mandatory (yes or no) and the purpose of the fee (actual procedure, extra services [eg, dietetic consultation]), use of facility, other or uncertain). The questionnaire was pilot tested for clarity and comprehension, and could be completed in less than $10 \mathrm{~min}$.

Patients were invited to participate using a modified Dillman protocol (9), and were mailed an invitation letter/consent form and questionnaire. If there was no reply within three weeks, respondents were mailed a postcard reminder. If necessary, a second complete survey package was mailed three weeks after the postcard. By completing and returning the questionnaire, patient consent to participate in the study was implicit. Completed questionnaires were received between January and May, 2009.

\section{Analysis}

Analyses were restricted to patients reporting their experience with colonoscopies in the past 10 years. Any colonoscopies that were not performed within a public hospital setting were considered to be 'nonhospital'. The characteristics of colonoscopies performed in a hospital were compared with those performed in a nonhospital setting. The associations between colonoscopy setting and the patients' demographic information, indication for procedure, wait time and follow-up interval to the next colonoscopy were measured using $\chi^{2}$ or Wilcoxon rank sum tests as appropriate.

Multivariable logistic regression analysis was used to examine the association between colonoscopy setting and 'appropriate' recommendations for the interval to the next colonoscopy in low-risk patients. A 10-year follow-up interval was selected to be appropriate for this population based on guidelines from American (4) and Canadian (10) subspecialty associations. The analysis was adjusted for age, sex, ethnicity, income and number of previous colonoscopies, and was performed on a subsample of patients without a family history of CRC or polyps, who underwent their most recent colonoscopy for screening purposes and reported a 'normal' result.

In the survey, participants checked the box beside the category (less than four weeks, four to eight weeks, or greater than eight weeks) that best reflected their wait time for colonoscopy. An ordinal logistic regression model was used to examine wait times in hospital versus nonhospital settings after adjusting for age, sex, ethnicity and income. Ordinal logistic regression analysis was used to account for the ordered nature of the wait time response variable (11). Under the proportional odds assumption, the OR for this model represented the odds of a patient reporting the next shorter wait time.

Analyses were performed using SAS version 9.2 (SAS Institute, USA).

\section{Sample size}

A calculated sample of 500 participants with history of colonoscopy was required to have $90 \%$ power with alpha of 0.05 , to detect a $15 \%$ difference between hospital and nonhospital settings in the proportion of low-risk patients recommended to undergo repeat colonoscopy at 10 years. This was based on an estimated 35\% of colonoscopies being performed in nonhospital settings (unpublished data from Toronto Central Local Health Integration Unit, Toronto, Ontario). After estimating a 50\% response rate and a 50\% prevalence of colonoscopy among participants, a total of 2000 surveys were produced. One hundred seventy-five respondents who underwent colonoscopy in nonhospital settings were expected, while 325 respondents who underwent colonoscopy in a hospital were expected.

\section{Ethics}

Approval was granted by the Research Ethics Boards of Women's College Hospital and the Toronto Academic Health Sciences Network (Toronto, Ontario).

\section{RESULTS}

A total of 3254 patients with a median age of 58 years (interquartile range 54 to 62 years) were eligible, $75 \%$ of whom were women. Of 2000 surveys distributed, 125 were returned due to incorrect addresses, and six patients were reported as deceased. Of the remaining 1869 survey questionnaires, 956 were completed, yielding a response rate of $51.2 \%$. Seventy-four per cent of these patients were women, with a median age of 59 years (interquartile range 54 to 64 years).

Of the 956 respondents, 821 reported that they underwent at least one CRC screening test in the previous 10 years, and many reported receiving multiple tests. Specifically, 689 underwent a colonoscopy, 361 underwent FOBT, 62 underwent a barium enema and 59 underwent a sigmoidoscopy. Of the 650 repondents who completed the survey item pertaining to the setting of their most recent colonoscopy, $16.9 \%(\mathrm{n}=110)$ underwent their most recent colonoscopy in a nonhospital setting. Of the 500 patients who reported the exact location of their most recent colonoscopy, 17 different hospitals and 13 different nonhospital clinics were described.

Table 1 compares the sociodemographic characteristics and relevant medical history of respondents who underwent their most recent colonoscopy in a hospital with those who received the procedure in a nonhospital setting. Women were more likely than men to undergo a colonoscopy in a hospital ( $77 \%$ versus $65 \% ; \mathrm{P}=0.01$ ), while patients with a history of two or more colonoscopies were less likely to have undergone their most recent colonoscopy in a hospital (34\% versus $46 \% ; \mathrm{P}=0.02$ ). No other significant differences were found between the two groups. In particular, no association was noted between report of symptoms and colonoscopy setting (69\% versus $64 \% ; \mathrm{P}=0.42)$, or between report of 'normal' results and colonoscopy setting (69\% versus $76 \% ; \mathrm{P}=0.20)$.

Table 2 summarizes the differences between hospital and nonhospital settings in recommended follow-up interval after a self-reported normal screening colonoscopy for patients without a family history of $\mathrm{CRC}$ or polyps. Persons receiving colonoscopy in a nonhospital facility were more likely to report a recommendation for a shorter interval to the next colonoscopy $(\mathrm{P}<0.0001)$. After adjustment for covariates in the multivariable model, among patients without a family history of CRC or polyps who had a normal screening colonoscopy, those who received their procedure in a nonhospital setting were less likely to be recommended a 10-year follow-up interval (OR 0.13 [95\% CI 0.04 to 0.47]) (Table 3). 
TABLE 1

Characteristics of respondents reporting colonoscopy within the past 10 years according to colonoscopy setting

\begin{tabular}{|c|c|c|c|}
\hline & \multicolumn{2}{|c|}{ Setting } & \multirow[b]{2}{*}{$\mathbf{P}$} \\
\hline & $\begin{array}{c}\text { Nonhospital } \\
(n=110)\end{array}$ & $\begin{array}{l}\text { Hospital } \\
(n=540)\end{array}$ & \\
\hline \multicolumn{4}{|l|}{ Demographics } \\
\hline Age, years, median (IQR) & $60(54-64)$ & $59(55-64)$ & 0.95 \\
\hline Female & $72(65)$ & $417(77)$ & 0.01 \\
\hline Single & $36(33)$ & $186(35)$ & 0.83 \\
\hline Caucasian & $92(84)$ & $456(84)$ & 0.89 \\
\hline Born in Canada & $72(65)$ & $332(62)$ & 0.52 \\
\hline Education & & & 0.19 \\
\hline High school incomplete & $2(2)$ & $11(2)$ & \\
\hline High school diploma & $7(6)$ & $78(15)$ & \\
\hline Attended college & $26(24)$ & $122(23)$ & \\
\hline College degree & $30(28)$ & $131(25)$ & \\
\hline Postgraduate degree & $44(40)$ & $192(36)$ & \\
\hline Annual household income, \$ & & & 0.17 \\
\hline 40,000 & $14(14)$ & $65(13)$ & \\
\hline $41,000-60,000$ & $7(7)$ & $76(16)$ & \\
\hline $61,000-80,000$ & $19(19)$ & $68(14)$ & \\
\hline $81,000-100,000$ & $14(14)$ & $64(13)$ & \\
\hline$>100,000$ & $45(45)$ & $216(44)$ & \\
\hline \multicolumn{4}{|l|}{ Medical history } \\
\hline Family history of CRC & $20(19)$ & $107(20)$ & 0.92 \\
\hline Family history of polyps & $31(30)$ & $111(21)$ & 0.13 \\
\hline $\begin{array}{l}\text { Two or more previous } \\
\text { colonoscopies }\end{array}$ & $51(46)$ & $183(34)$ & 0.02 \\
\hline \multicolumn{4}{|l|}{ Colonoscopy indication } \\
\hline Screening (no symptoms) & $67(64)$ & 347 (69) & 0.42 \\
\hline \multicolumn{4}{|l|}{ Recent colonoscopy result } \\
\hline Normal & $82(76)$ & $351(69)$ & 0.20 \\
\hline
\end{tabular}

Data presented as $n$ (\%) unless otherwise indicated. Number of respondents within categories may not add to column totals because not all respondents completed all questions. Significance testing is based on the number of completed questions. Fisher's exact test was used to assess for differences between categorical variables. Wilcoxon's rank sum test was used for continuous variables (age). CRC Colorectal cancer; IQR Interquartile range

TABLE 2

Recommended interval before next colonoscopy according to colonoscopy setting following a normal screening colonoscopy in patients with no family history of polyps or colorectal cancer

\begin{tabular}{lcc}
\hline \multirow{2}{*}{$\begin{array}{l}\text { years } \\
\text { yeal, }\end{array}$} & \multicolumn{2}{c}{ Setting, $\mathbf{n}(\%)$} \\
\hline$<3$ & $2(6)$ & Hospital $(\mathbf{n}=\mathbf{1 6 0})$ \\
$3-5$ & $21(60)$ & $7(4)$ \\
$6-9$ & $2(6)$ & $12(25)$ \\
10 & $4(11)$ & $77(48)$ \\
Unsure & $6(17)$ & $24(15)$ \\
\hline
\end{tabular}

$P<0.0001$ by Fisher's exact test

Table 4 summarizes the reported differences in wait time for a colonoscopy performed in a hospital versus a nonhospital setting, stratified according to presence of symptoms. For patients undergoing a screening colonoscopy, the nonhospital clinics had shorter wait times $(\mathrm{P}=0.01)$; however, in symptomatic patients, there was no association between wait times and setting $(\mathrm{P}=0.20)$. After adjusting for covariates, the nonhospital setting (OR 2.11 [95\% CI 1.28 to 3.47]) was associated with shorter wait times for screening colonoscopies, but not for symptomatic patients (OR 1.74 [95\% CI 0.88 to 3.43]) (Table 5).
TABLE 3

Multivariate regression analysis of patient characteristics and colonoscopy setting associated with a recommended 10-year interval for repeat colonoscopy in patients with no family history of polyps or colorectal cancer who reported a normal result

\begin{tabular}{|c|c|c|}
\hline & OR $(95 \% \mathrm{Cl})$ & $\mathbf{P}$ \\
\hline \multicolumn{3}{|l|}{ Colonoscopy setting } \\
\hline Nonhospital & $0.13(0.04-0.47)$ & 0.002 \\
\hline Hospital & 1 & \\
\hline Age, per 5-year increase & $0.96(0.71-1.30)$ & 0.778 \\
\hline \multicolumn{3}{|l|}{ Sex } \\
\hline Male & $0.80(0.38-1.65)$ & 0.536 \\
\hline Female & 1 & \\
\hline \multicolumn{3}{|l|}{ Ethnicity } \\
\hline Caucasian & $0.91(0.38-2.18)$ & 0.826 \\
\hline Other ethnicity & 1 & \\
\hline Previous colonoscopies, $\mathrm{n}$ (per colonoscopy) & $0.37(0.17-0.78)$ & 0.009 \\
\hline
\end{tabular}

TABLE 4

Reported wait times for colonoscopy according to indication and setting

\begin{tabular}{lccccc}
\hline & \multicolumn{2}{c}{ Symptomatic } & & \multicolumn{2}{c}{ Screening } \\
\cline { 2 - 3 } \cline { 5 - 6 } Wait time, & $\begin{array}{c}\text { Nonhospital } \\
\text { weeks }\end{array}$ & $\begin{array}{c}\text { Hospital } \\
(\mathbf{n}=39)\end{array}$ & & $\begin{array}{c}\text { Nonhospital } \\
(\mathbf{n}=69)\end{array}$ & $\begin{array}{c}\text { Hospital } \\
(\mathbf{n}=350)\end{array}$ \\
\hline$<4$ & $21(54)$ & $69(41)$ & & $29(42)$ & $96(27)$ \\
$4-8$ & $9(23)$ & $36(21)$ & & $19(28)$ & $79(23)$ \\
$>8$ & $9(23)$ & $63(38)$ & & $21(30)$ & $175(50)$ \\
\hline
\end{tabular}

Data presented as $n$ (\%). $P=0.202$ for the symptomatic group by Fisher's exact test; $P=0.008$ for the screening group by Fisher's exact test

Of 110 participants who underwent a colonoscopy in a nonhospital setting, 90 responded to a question regarding the referral source. Of these, 48 respondents $(53.3 \%)$ reported referral by their family physician, $13(14.4 \%)$ reported referral by the family physician at the patient's request, nine $(10 \%)$ reported referral by the specialist providing the colonoscopy from the hospital to a nonhospital clinic, eight $(8.9 \%)$ reported referral as a component of an 'executive physical examination' and eight $(8.9 \%)$ reported self-referral.

Of 110 participants who underwent a colonoscopy in a nonhospital setting, 82 responded to a question regarding fees, with $26(31.7 \%)$ reporting payment. Of those who paid a fee, 19 respondents $(73.1 \%)$ believed that the fee was mandatory. Regarding the purpose of the fee, 11 respondents $(42.3 \%)$ reported that the fee had been charged for extra services (eg, dietetic counselling) and eight (30.8\%) reported that the fee had been charged for the procedure or facility.

\section{DISCUSSION}

In the present study, a postal survey was used to compare the experiences of patients undergoing colonoscopy in nonhospital settings with those who received the procedure within hospitals. Compared with hospitals, nonhospital settings offered shorter wait times for those undergoing screening colonoscopy but were less likely to adhere to guidelines regarding the interval to the next colonoscopy in low-risk patients.

Evidence-based guidelines $(12,13)$ recommend that patients who have no family history of CRC or polyps, and who have a normal screening colonoscopy should have a follow-up procedure in 10 years; the guidelines have not changed with respect to this recommendation for more than a decade (14). In our study, $91.4 \%$ of patients who underwent colonoscopy in nonhospital settings with normal screening results were asked to return in less than 10 years. To our knowledge, the present study is the first to demonstrate a significant difference in 
follow-up intervals between colonoscopies performed in hospital and nonhospital settings. The difference between settings with respect to follow-up interval was not explained by the data we collected regarding patient or clinical characteristics. Because colonoscopy is expensive and can be associated with serious complications (15), an excess number of colonoscopy procedures are undesirable for both the health care system and the patient.

In the present study, patients in nonhospital settings had shorter wait times for screening colonoscopy. However, the clinical advantage of providing shorter wait times for screening colonoscopies is questionable. Meanwhile, some study participants perceived an obligation to pay a mandatory fee at nonhospital clinics. This perception of mandatory fees by the patient may represent a barrier to access to care. Therefore, nonhospital facilities should reinforce the optional nature of any fees that are being charged directly to patients for medically necessary services.

Although the majority of referrals to nonhospital settings were from family physicians, $10 \%$ of participants reported that they were referred from the hospital to the nonhospital setting by their specialist. Our study could not discern whether these self-referrals represented the use of the nonhospital setting as a 'safety-valve' for unacceptable wait times in the hospital or whether it reflected a potential conflict of interest (16).

An important limitation of the present study was the use of selfreported data. However, a previous Canadian study (17) compared patient self-report and chart audit for CRC screening and found it to be generally accurate. It is not believed that the reliability of selfreport data would be systematically different due to the setting or the geographical location of colonoscopy.

In addition, we found very high rates of compliance with CRC screening. This may be due, in part, to response bias, but the rates are consistent with recent internal audits conducted for pay-forperformance purposes. The high frequency of CRC screening with colonoscopy and the lower than expected use of out-of-hospital facilities may, in part, be explained by the concurrent recruitment for a colonoscopy screening study being conducted at a public hospital associated with our family practice unit. However, a greater than normal availability of colonoscopy services in hospitals would be most likely to bias our study results toward no difference in wait times (especially for symptomatic patients) and recommended follow-up intervals. This suggests that the differences in care received by patients in hospital and nonhospital settings may be greater than the results of our study indicate. Further research to investigate the reasons for this disparity is needed, and may provide the basis for strategies to ensure more consistent delivery of colonoscopy services across settings and to improve the appropriateness of patient recall after colonoscopy in general.

\section{SUMMARY}

Although an increasing number of patients are undergoing procedures such as colonoscopy in nonhospital settings in Canada, the literature on this topic remains sparse and is limited mostly to research using administrative databases.

We used a large cross-sectional survey to examine the experiences of patients undergoing screening colonoscopy procedures in hospital and nonhospital settings. Our key findings have the following important implications for health care costs and patient safety: wait times were shorter at nonhospital clinics, but only for asymptomatic patients; some patients at nonhospital clinics perceived that paying a fee was mandatory; and nonhospital clinics were far less likely to adhere to guidelines for low-risk patients regarding the recommended follow-up interval to the next colonoscopy.

The present study was the first to identify that nonhospital settings are less likely to adhere to evidence-based guidelines for follow-up intervals. Unnecessary procedures carry direct costs to the system and elevated risk for patients.
TABLE 5

Ordinal logistic regression analysis of patient characteristics and colonoscopy setting associated with patient-reported wait times for screening colonoscopy or for symptomatic colonoscopy

\begin{tabular}{|c|c|c|}
\hline & \multicolumn{2}{|c|}{ Shorter wait time for screening colonoscopy } \\
\hline & OR $(95 \% \mathrm{Cl})$ & $\mathbf{P}$ \\
\hline \multicolumn{3}{|l|}{ Colonoscopy setting } \\
\hline Nonhospital & $2.11(1.28-3.47)$ & 0.004 \\
\hline Hospital & 1.00 & \\
\hline Age, per 5-year increase & $1.2(1.02-1.43)$ & 0.033 \\
\hline \multicolumn{3}{|l|}{ Sex } \\
\hline Male & $0.83(0.53-1.29)$ & 0.396 \\
\hline Female & 1.00 & \\
\hline \multicolumn{3}{|l|}{ Ethnicity } \\
\hline Caucasian & $1.21(0.73-2.02)$ & 0.458 \\
\hline Other ethnicity & 1.00 & \\
\hline \multicolumn{3}{|c|}{ Yearly household income, \$ } \\
\hline$\geq 100,000$ & $0.99(0.67-1.47)$ & 0.963 \\
\hline \multirow[t]{3}{*}{$<100,000$} & 1.00 & \\
\hline & \multicolumn{2}{|c|}{ Shorter wait time for symptomatic colonoscopy } \\
\hline & OR $(95 \% \mathrm{Cl})$ & $\mathbf{P}$ \\
\hline \multicolumn{3}{|l|}{ Colonoscopy setting } \\
\hline Nonhospital & $1.74(0.88-3.43)$ & 0.112 \\
\hline Hospital & 1.00 & \\
\hline Age, per 5-year increase & $1.03(0.84-1.27)$ & 0.770 \\
\hline \multicolumn{3}{|l|}{ Sex } \\
\hline Male & $1.38(0.72-2.63)$ & 0.335 \\
\hline Female & 1.00 & \\
\hline \multicolumn{3}{|l|}{ Ethnicity } \\
\hline Caucasian & $0.99(0.49-1.99)$ & 0.973 \\
\hline Other ethnicity & 1.00 & \\
\hline \multicolumn{3}{|c|}{ Yearly household income, \$ } \\
\hline$\geq 100,000$ & $0.69(0.37-1.29)$ & 0.245 \\
\hline$<100,000$ & 1.00 & \\
\hline
\end{tabular}

For 'screening': $c=0.591$, score test for proportional odds assumption $P=0.873$. For 'symptomatic': $c=0.562$, score test for proportional odds assumption $P=0.946$

ACKNOWLEDGEMENTS: The authors are grateful for the support of this project received from Cancer Care Ontario and thank the patients at the Women's College Hospital (Toronto, Ontario) family practice for their participation.

FUNDING: Financial support for this study was provided by Cancer Care Ontario. Dr Noah Ivers is supported by a fellowship grant in clinical research from the Canadian Institutes of Health Research.

CONFLICTS OF INTEREST: The authors have no financial disclosures or conflicts of interest to declare.

\section{REFERENCES}

1. Canadian Cancer Society's Steering Committee: Canadian Cancer Statistics 2010. Toronto: Canadian Cancer Society, 2010. $<$ http://www.cancer.ca/Canada-wide/About $\% 20$ cancer/Cancer $\% 20$ statistics/Canadian\%20Cancer\%20Statistics.aspx> (Accessed on June 6, 2010).

2. Hewitson P, Glasziou P, Watson E, Towler B, Irwig L. Cochrane systematic review of colorectal cancer screening using the fecal occult blood test (hemoccult): An update. Am J Gastroenterol 2008;103:1541-9. 
3. Atkin WS, Edwards R, Kralj-Hans I, et al; UK Flexible Sigmoidoscopy Trial Investigators. Once-only flexible sigmoidoscopy screening in prevention of colorectal cancer:

A multicentre randomised controlled trial. Lancet 2010;375:1624-33.

4. Levin B, Lieberman DA, McFarland B, et al. Screening and surveillance for the early detection of colorectal cancer and adenomatous polyps, 2008: A joint guideline from the American Cancer Society, the US Multi-Society Task Force on Colorectal Cancer, and the American College of Radiology. Gastroenterology. 2008;134:1570-95.

5. Alharbi O, Rabeneck L, Paszat L, et al. Factors associated with colonoscopy performed outside of hospital. Can J Gastroenterol 2010;24:419-24.

6. Sharara N, Adam V, Crott R, Barkun AN. The costs of colonoscopy in a Canadian hospital using a microcosting approach. Can J Gastroenterol 2008;22:565-70.

7. Shah HA, Paszat LF, Saskin R, Stukel TA, Rabeneck L. Factors associated with incomplete colonoscopy:

A population-based study. Gastroenterology 2007;132:2297-303.

8. Bressler B, Paszat LF, Chen Z, Rothwell DM, Vinden C, Rabeneck L. Rates of new or missed colorectal cancers after colonoscopy and their risk factors: A population-based analysis. Gastroenterology 2007;132:96-102.

9. Anema MG, Brown BE. Increasing survey responses using the total design method. J Contin Educ Nurs 1995;26:109-14.
10. Leddin D, Hunt R, Champion M, et al; Canadian Association of Gastroenterology; Canadian Digestive Health Foundation. Canadian Association of Gastroenterology and the Canadian Digestive Health Foundation: Guidelines on colon cancer screening. Can J Gastroenterol 2004;18:93-9.

11. Allison PD. Logistic Regression Using the SAS System. Cary: SAS Press, 1999.

12. Singh H, Turner D, Xue L, Targownik LE, Bernstein CN. Risk of developing colorectal cancer following a negative colonoscopy examination: Evidence for a 10-year interval between colonoscopies. JAMA 2006;24:2366-73.

13. Imperiale TF, Glowinski EA, Lin-Cooper C, Larkin GN, Rogge JD, Ransohoff DF. Five-year risk of colorectal neoplasia after negative screening colonoscopy. N Engl J Med 2008;359:1218-24.

14. Winawer SJ, Fletcher RH, Miller L, et al. Colorectal cancer screening: Clinical guidelines and rationale. Gastroenterology 1997;112:594-642.

15. Singh H, Penfold RB, DeCoster C, et al. Colonoscopy and its complications across a Canadian regional health authority. Gastrointest Endosc 2009;69(3 Pt 2):665-71.

16. Choudhry S, Choudhry NK, Brown AD. Unregulated private markets for health care in Canada? Rules of professional misconduct, physician kickbacks and physician self-referral. CMAJ 2004;170:1115-8

17. Khoja S, McGregor SE, Hilsden RJ. Validation of self-reported history of colorectal cancer screening. Can Fam Physician 2007;53:1192-7. 


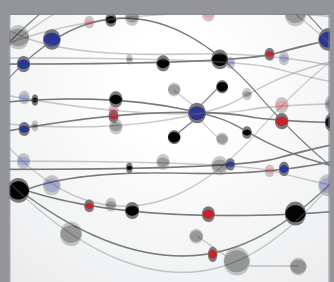

The Scientific World Journal
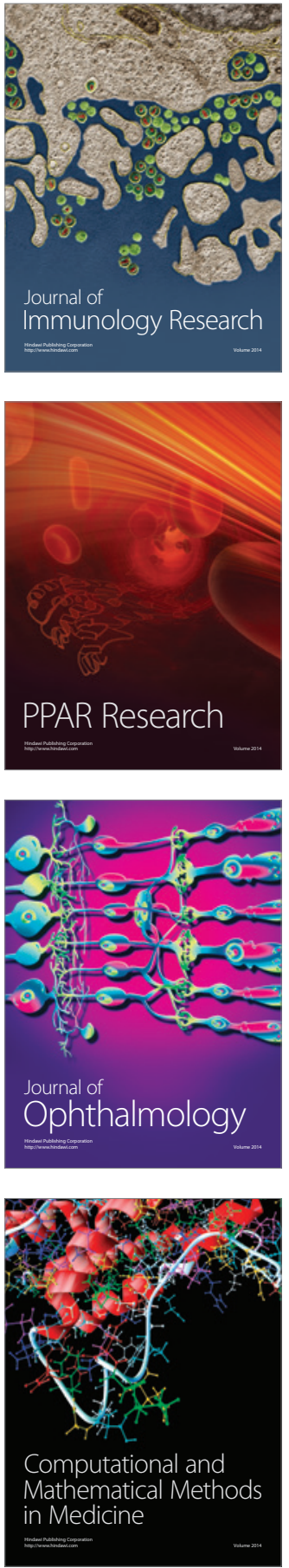

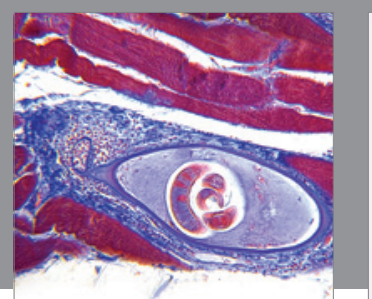

Gastroenterology Research and Practice

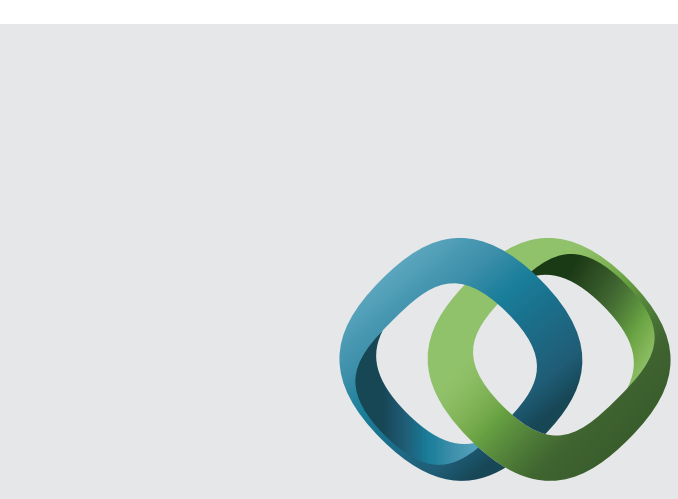

\section{Hindawi}

Submit your manuscripts at

http://www.hindawi.com
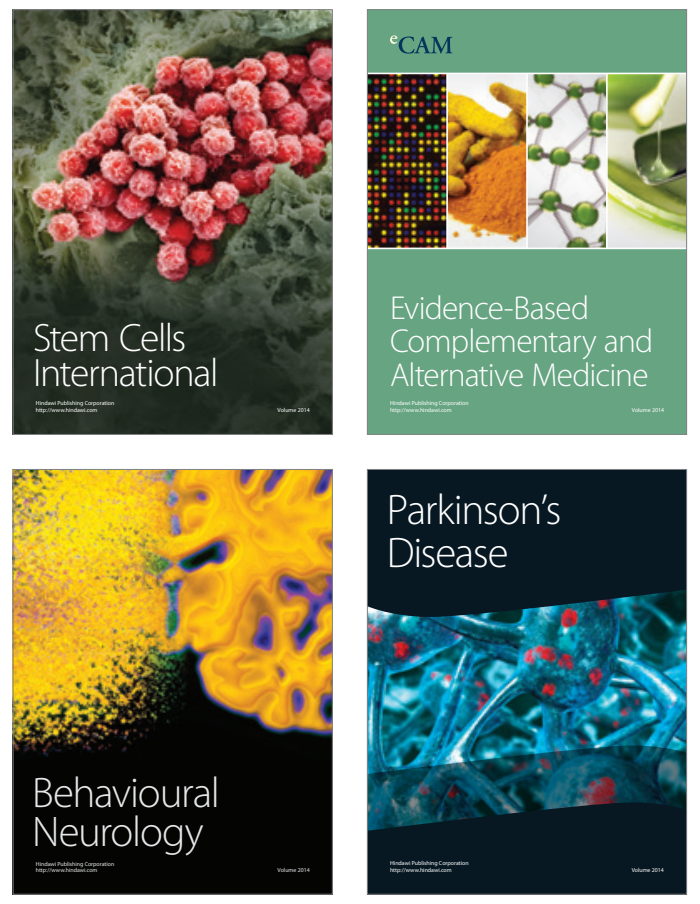
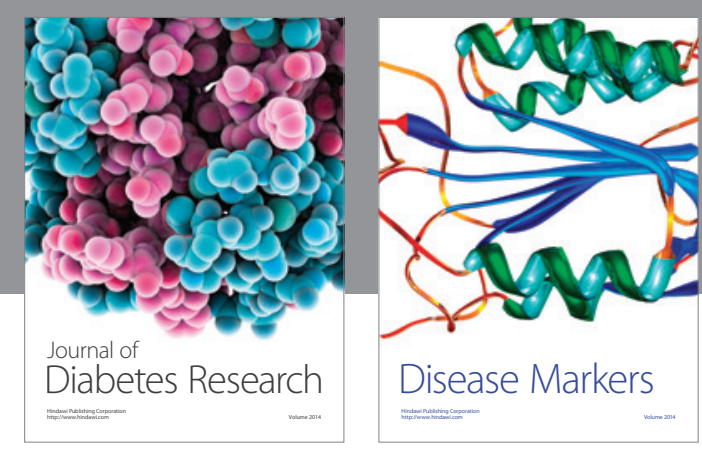

Disease Markers
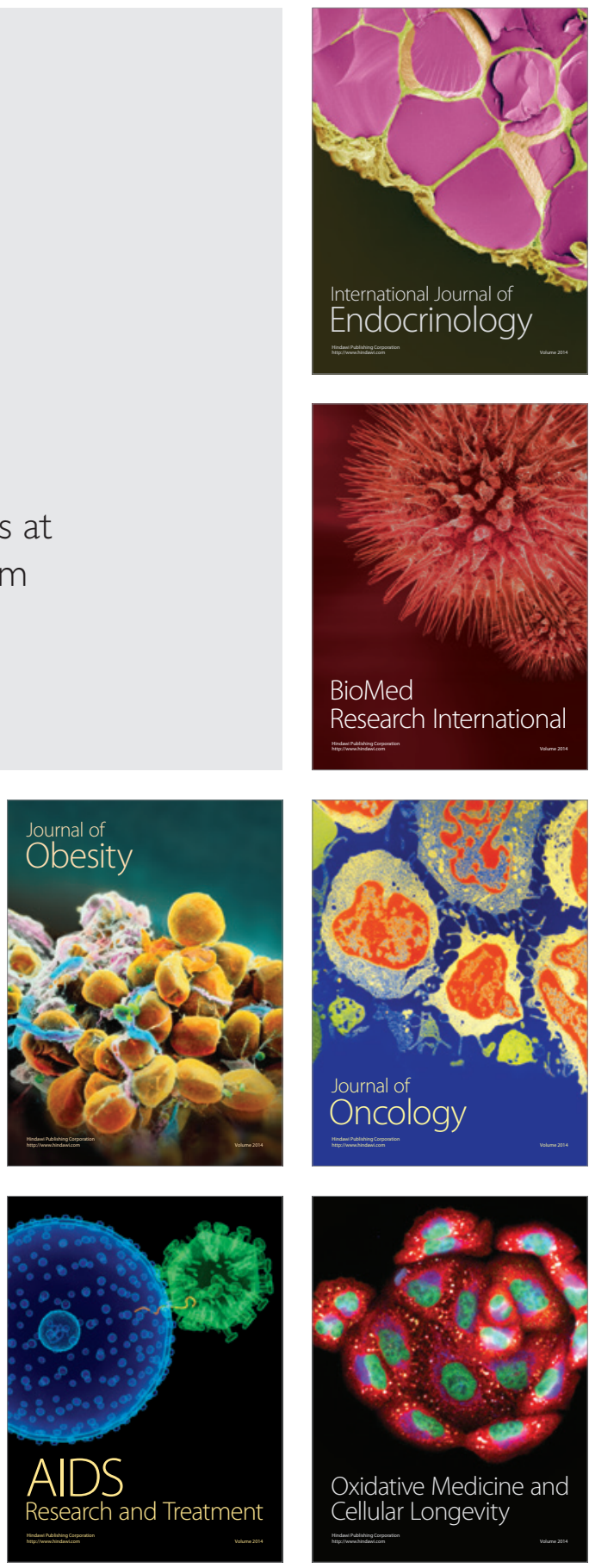